\title{
A revolução portuguesa de 1974-1975 e o seu impacto na transição espanhola para a democracia vista através da imprensa clandestina espanhola
}

\author{
RaQuel Varela \\ Investigadora de História Contemporânea na Universidade Nova de Lisboa

\begin{abstract}
The Portuguese revolution of 1974-1975 and its impact of the Spanish clandestine press
\end{abstract} \\ on the Spanish transition to democracy through the eyes
}

\begin{abstract}
RESUMO
A revolução portuguesa de 1974-1975 teve impacto na vizinha Espanha a nível político e institucional, nomeadamente no movimento sindical, na Igreja Católica e nas Forças Armadas. Nesta comunicação pretendemos estudar esta influência através da análise de três jornais clandestinos: El Socialista, do Partido Socialista Operário Espanhol, Mundo

Obrero, do Partido Comunista de Espanha, Combate, da Liga Comunista Revolucionária e La Batalla, do Partido Operário de Unificação Marxista.

Dois destes partidos, o PSOE e o PCE, tiveram um papel essencial na negociação

que levou aos Pactos de Moncloa, na discussão e aprovação da Constituição de 1978 e na consolidação da Espanha como uma democracia ocidental.

Analisaremos como é que a esquerda espanhola ilegalizada compreendeu e reagiu aos acontecimentos que ocorriam em Portugal entre o golpe que destronou

o regime de Salazar e Caetano a 25 de Abril de 1974 e o fim da crise
\end{abstract} revolucionária a 25 de Novembro de 1975.

\section{ABSTRACT}

The Portuguese revolution of the years 1974-1975 had an impact in neighbouring Spain at the political and institutional levels, on the Trades Unions, the Catholic Church and the Armed Forces. In this paper we intend to study these influences through the analysis of four clandestine newspapers - El Socialista (PSOESocialist Party), Mundo Obrero (PCESpanish Communist Party), Combate (LCR-Revolutionary Communist League) and La Batalla (POUM-Unified Marxist Workers Party).

Two of these political parties, PSOE and $P C E$, will play an essential role in the talks leading to the Moncloa Pacts, the making and passing of a new Constitutional Act and the consolidation of Spain as a western style democracy.

We'll analyse how the illegalized Spanish left understood and reacted to the events taking place in Portugal between the coup that overthrew the Salazar and Caetano regime on 25 April 1974 and the end of the revolutionary crisis on 25 November 1975. 
PALABRAS CLAVE revolução portuguesa de 1974-1975, o seu impacto na transição espanhola, democracia, imprensa clandestina espanhola.
KEY WORDS

The Portuguese revolution of 1974-75, its impact on the Spanish transition, democracy, the Spanish clandestine press.

A revolução portuguesa de 1974-1975 teve impacto na vizinha Espanha a nível político e institucional, nomeadamente no movimento sindical, na Igreja Católica e nas Forças Armadas. Nesta comunicação pretendemos estudar esta influência através da análise de quatro jornais clandestinos - El Socialista, do Partido Socialista Operário Espanhol, Mundo Obrero, do Partido Comunista de Espanha, Combate, da Liga Comunista Revolucionária, e La Batalla, do Partido Operário de Unificação Marxista.

Dois destes partidos, PSOE e PCE, tiveram um papel essencial na negociação que levou aos Pactos de Moncloa, na discussão e aprovação da Constituição de 1978 e na consolidação da Espanha como uma democracia ocidental.

Analisaremos como é que a esquerda espanhola ilegalizada compreendeu e reagiu aos acontecimentos que ocorriam em Portugal entre o golpe que destronou o regime de Salazar e Caetano a 25 de Abril de 1974 e o fim da crise revolucionária a 25 de Novembro de 1975.

\section{A REVOLUÇÃO DOS CRAVOS}

No dia 25 de Abril de 1974 um golpe levado a cabo pelo Movimento das Forças Armadas (MFA) põe fim à ditadura portuguesa. De imediato, e contra a vontade dos militares, inicia-se um processo revolucionário. A revolução portuguesa, apesar de se dar num país semi-periférico, reveste historicamente um carácter especial na história das revoluções do século XX, por uma combinação de factores que a tornaram no movimento social mais radicalizado da Europa do pós-guerra (Cabral, 2004: 1; Arcary, 2004). Por quatro factores: a crise de acumulação mundial 1973-75; a combinação da luta anticolonial com a revolução na metrópole e viceversa, o impacto da revolução na luta pela independência; o efeito que a guerra teve na hierarquia militar e o carácter social da revolução - as tarefas «reformistas", no sentido clássico do termo (nacionalizações, reforma agrária, melhoria dos salários), ganharam uma dimensão revolucionária porque foram conquistadas contra a burguesia, com métodos próprios do movimento operário (greves, ocupações de terras e fábricas) e, em muitos casos, através de organismos autónomos de trabalhadores, de assalariados agrícolas e, em certo momento, de soldados.

A revolução portuguesa surge no meio da crise económica que se inicia em 1973 e que resulta numa recessão mundial, a primeira do pós-guerra, com uma 
queda abrupta do PIB dos países centrais e, ainda mais drástica nos países semiperiféricos: em Portugal a taxa de variação do PIB passa de 11,2\% em 1973 para 1,1\% em 1974 e $-4,3 \%$ em 1975. A existência desta crise coloca frente a frente as lutas dos trabalhadores pelo direito ao emprego, aumentos salariais, extensão de direitos sociais e os donos das fábricas e empresas empenhados em reduzir a produção (consequentemente a força de trabalho e os salários) como forma de repor as condições de acumulação e de saída da crise.

Outro factor determinante na revolução portuguesa é a luta anticolonial. É a prolongada luta dos movimentos de libertação nas colónias que vai determinar o fim da ditadura portuguesa, pela oposição à guerra da oficialidade intermédia e alguns quadros superiores. Esta característica liga-se a outra: a classe dominante tem dificuldade em mobilizar o Exército contra a revolução e sectores significativos das Forças Armadas acabam por se radicalizar. A revolução política transformouse numa revolução social que conseguiu o fim da guerra colonial, a independência das colónias, a reforma agrária, direito ao trabalho, melhoria dos salários, instituição da educação e saúde públicas de qualidade e democratizadas a toda a população, e acesso à habitação.

Neste período os trabalhadores autoorganizaram-se em comissões, de trabalhadores e de moradores, ocuparam terras e, dentro do aparelho militar, chegou a haver uma organização de soldados autónoma, os SUV, além do clima «deliberativo" que tanto incomodava as hierarquias, com as ADUs (Assembleias Democráticas de Unidade), nas principais unidades militares. Entre Julho e Novembro de 1975 Portugal viveu uma crise revolucionária, em que o deslocamento do Estado ou um golpe contra-revolucionário estavam em cima da mesa.

A revolução portuguesa de 1974-75 teve uma profunda influência na transição espanhola. A forma negociada - entre as elites franquistas e os principais partidos oposicionistas, o PSOE e o PCE - da mudança de regime em Espanha deveu-se em grande medida ao temor de contágio da revolução portuguesa. Autores como Josep Sanchez Cervelló (1993) e Encarnacion Lemus (2004) estudaram a influência da revolução portuguesa na transição espanhola, salientando o medo de contágio que as elites em Espanha e nos principais países centrais temiam. Num quadro mundial de profundas transformações políticas e económicas, na Península Ibérica, as duas últimas ditaduras da família das ditaduras fascistas que emergiram no período entre guerras caem, quase em simultâneo - junto com a Grécia dos coronéis.

Meses depois do 25 de Abril de 1974, em Março de 1975, o PSOE, em Espanha, é legitimado: ainda ilegal passa a poder usar os seus símbolos e bandeiras na rua (Cervelló, 1993: 376); a primeira vez que o Governo espanhol usa um computador é em 1975 para fazer uma base de dados de todos os militares da UMD (União Militar Democrática) - um grupo de oficiais e sargentos do Exército, cerca de 200, com pequenas ramificações na Guardia Civil, que se tinha organizado com um programa inspirado directamente no do Movimento das Forças Ar- 
madas (MFA), o movimento de oficiais intermédios que tinha feito o golpe contra a ditadura de Salazar; na sequência do golpe de 11 de Março, Spínola exila-se em Espanha, país que serve de base de apoio ao ELP (Exército de Libertação Português), uma milícia ultra-reaccionária portuguesa; em Setembro de 1975, a Embaixada e o Consulado de Espanha em Lisboa são destruídos e queimados por militantes de extrema-esquerda em resposta à execução de militantes da esquerda por Franco; em Outubro de 1975 Marrocos expulsa o Exército espanhol do Sara (até então espanhol) e a burguesia espanhola é incapaz de mobilizar o seu Exército contra.

A influência também se verá em factores culturais/sociais como as feiras do livro português, organizadas naquele biénio em Espanha por várias cidades, ou na romaria de espanhóis a Lisboa, que faziam filas à porta dos cinemas para verem a famosa cena de sodomia entre Marlon Brando e Maria Schneider em O Último Tango em Paris, de Bertolluci, proibido em Espanha; e também nas dezenas de cartazes que a extrema-esquerda portuguesa pintou em solidariedade com os presos políticos espanhóis.

As fontes oficiais, num período de profunda perturbação social e mudanças muito rápidas - às vezes de horas - dificilmente registam o movimento social que levou as instituições e/ou sujeitos representativos (partidos políticos, sindicatos, etc.) a agir em determinada direcção ${ }^{1}$. A imprensa pode ser uma ajuda preciosa ao alcance dos historiadores contemporâneos. Alvo da lupa crítica, como qualquer outra fonte, ela pode dar-nos algumas dimensões por vezes ignoradas noutros registos.

Um período revolucionário ou de confronto social caracteriza-se por interromper o conservadorismo social que caracteriza as sociedades em geral: As revoluções políticas, escreve o historiador Valério Arcary, «têm sido, no entanto, uma das formas a que as sociedades contemporâneas recorreram para resolver tarefas históricas que permaneceram pendentes. A mudança, no entanto, só excepcionalmente assume a forma revolucionária. É preciso que todas as outras vias tenham sido antes bloqueadas e esgotadas ${ }^{2}$. A história dá então um passo de gigante e os acontecimentos sucedem-se à velocidade da luz: nos 19 meses do período revolucionário português houve 6 governos e 3 golpes de Estado. Se isto foi assim no campo institucional muito mais o foi na arena dos movimentos so-

1 Chris Harman na sua monumental obra A People's History of the World dá-nos uma dimensão de como a história não deve regressar ao passado positivista e à história decidida por um grupo restrito de indivíduos e recupera o papel dos grandes movimentos sociais como o esqueleto da sociedade: «This approach does not deny the role of individuals or the ideas they propagate. What it does do is insist that the individual or idea can only play a certain role because of the preceding material development of society, of the way people make their livelihoods, and of structure of classes and state. The skeleton is not the same as the living body. But without the skeleton the body would have no solidity and could not survive» in HARMAN, Chris, A People's History of the World, London and Sidney, Bookmarks,2002, p. IV.

2 ARCARY, Valério, As Esquinas Perigosas da História. Situações Revolucionárias em Perspectiva Marxista, São Paulo, Xamã, 2004, p.27. 
ciais. Escolher a imprensa como fonte é recuperar parte deste dia a dia da revolução portuguesa e o seu impacto, quase dia a dia, na vizinha Espanha que, na base da transição, teve presente um poderoso e violento movimento social como ilustram as obras de Duran Muñoz ${ }^{3}$ e de Xavier Domènech Sampere ${ }^{4}$, entre outras. Escolher a imprensa como fonte é de alguma forma abrir as portas à recuperação dos movimentos sociais, do imprevisto, da dinâmica de transformação que viveram os dois regimes neste período. Como argumenta Gabriel Vitullo, «A necessidade de resgatar e dar maior atenção às variáveis estritamente políticas - antes não tidas em conta - não pode autorizar que a democratização seja vista apenas como o resultado de uma eleição ou opção estratégica das elites dirigentes, omitindo o restante da sociedade, os sectores populares e a própria história, como fica manifesto na colectânea de Higley e Gunther (1992), cujo objectivo primordial parece ser o de adoptar o compromisso das elites como pré-condição fundamental para a consolidação da democracia. Como criteriosamente argumenta Bunce (2000, p. 635), ficar nesse único plano de análise implica dizer que são as elites e não a sociedade, a política e não a economia, os processos internos e não as influências internacionais, os que constituem os factores cruciais da democratização e que, portanto - agregaríamos - a democracia pode ser confeccionada ou desmontada de acordo com as opções ou decisões tomadas por um reduzido grupo de lideranças políticas» 5 .

Neste artigo analisámos a imprensa clandestina: El Socialista do PSOE (Partido Socialista Operário Espanhol), Mundo Obrero do PCE (Partido Comunista de España) e dois jornais de pequenos partidos de extrema-esquerda, o Combate da LCR (Liga Comunista Revolucionária) e La Batalla do POUM (Partido Operário de Unificação Marxista). A sua importância é central para a transição espanhola, seja pelas opiniões diferentes, em alguns casos, das veiculadas na imprensa legal, seja porque dois dos partidos aqui analisados, PSOE e PCE, serão co-protagonistas da transição pactada e co-protagonizarão a assinatura dos pactos de Moncloa, em Outubro de 1977, a institucionalização da transição no plano sócio-económico.

\section{O MEDITERRÂNEO «VERMELHO»}

Na década de 60 do século XX dão-se alterações económicas na Península Ibérica que provocaram mudanças substanciais nas sociedades do Sul da Europa.

\footnotetext{
${ }^{3}$ MUÑOZ, Rafael Durán, (2000), Contención y Transgresión, Las Movilizaciones Sociales y el Estado en las Transiciones Española e Portuguesa, Madrid, CEPC.

${ }^{4}$ SAMPERE, Xavier Domènech, «El Cambio Político (1962-1976). Materiales para una Perspectiva desde abajo» in Historia del Presente, n॰1, 2002, pp.46-67.

${ }_{5}^{5}$ VITULLO, Gabriel E. Transitologia, consolidologia e democracia na América Latina: uma revisão crítica. Rev. Sociol. Polit. [online]. 2001, no. 17 [citado 2007-02-12], pp. 53-60. Disponível em: <http://www.scielo.br/scielo.php?script=sci_arttext\&pid=S0104-44782001000200006\&lng=pt\&nrm=iso>. ISSN 0104-4478. doi: 10.1590/S0104-44782001000200006
} 
A título de exemplo - e segundo os estudos feitos por Hermínio Martins ${ }^{6}$ e António Barreto ${ }^{7}$ - refira-se que a população que trabalhava no sector primário passou de 42,8\% em 1960 para 29,8\% em 1970 e 10,9\% em 1991. Em Espanha «o crescimento económico transformou a sociedade espanhola. Ao contrário da exaltação da vida rural pelo regime, o campo esvaziou-se dos seus habitantes ${ }^{8}$ ", escreve Sebastian Balfour. O desenvolvimento económico, o crescimento do sector industrial e da classe operária urbana e a crise iniciada nos anos 70 são tão mais importantes quando em Espanha, segundo vários autores, entre eles Paloma Aguilar e Ernest Lluch, a memória da vitória republicana e da revolução espanhola estava associada à crise de 29: «esta crisis no podia dejar de evocar aquella otra que había seguido al crack de 19299» (Paloma Aguilar); «uno de los factores que había atraído menos atención de los estudiosos, pero que había calado profundamente entre la gente, era el impacto desfavorable de la crisis de 1929 en la andadura del gran precedente republicano ${ }^{10}$ ». (Ernest Lluch).

No plano político as transformações não são menos espectaculares: os EUA estavam a perder a guerra do Vietname, que entra na sua fase final na mesma altura em que rebenta o escândalo Watergate que leva à demissão de Nixon em Agosto de 1974. A Inglaterra vivia aquilo que Giuseppe Mammarella chama os «anos mais difíceis ${ }^{11}$ » com um aumento dos conflitos de classe em sectores muito fortes do movimento operário como os mineiros. Em 1973, um golpe levado a cabo por Augusto Pinochet com o apoio dos EUA e com empenhamento pessoal de Henry Kissinger derruba o governo democraticamente eleito de frente popular de Salvador Allende, instaurando uma das ditaduras mais sangrentas da América Latina, que matou cerca de 30000 pessoas. No Médio Oriente, em Outubro de 1973 rebenta a guerra do Yom Kippur que opõe Israel ao Egipto e à Síria e ainda no mesmo ano o choque petrolífero, sintoma de uma economia em crise.

Os Estados Unidos da América dão provas de ter compreendido a importância do «efeito dominó»: «Este país [EUA] alegre e confiante começou a preocupar-se com o avanço dos peões comunistas no enorme tabuleiro de xadrez em que se converteu o Mundo. A questão de Portugal e a sua viragem normal à extrema-esquerda pró-comunista começa a tomar forma, temendo que a teoria do dominó

${ }^{6}$ MARTINS, Hermínio, Classe, Status e Poder, Lisboa, ICS, 1998, p.113.

7 BARRETO, António, Portugal Contemporâneo (Coord. António Costa Pinto), Lisboa, Dom Quixote, 2005, p. 146.

8 BALFOUR, Sebastian, História Concisa de Espanha (Coord. Raymond Carr), Lisboa, EuropaAmérica, 2004, p. 247.

9 Aguilar, Paloma Fernández, Memoria y Olvido de la Guerra Civil Española, Madrid, Alianza Editorial, 1996, p. 211.

10 LLUCH, Ernest, «Transición Económica Y Transición Política: La Anomalia 1978-1980» in História de la Transición 1975-1986 (Eds Javier Tusell y Álvaro Soto), Madrid, Alianza Universidad, 1996, pp.252.

11 MAMMARELLA, Giuseppe, Historia de Europa Contemporánea desde 1945 hasta Hoy, Barcelona, Ariel, 1996, p.321. 


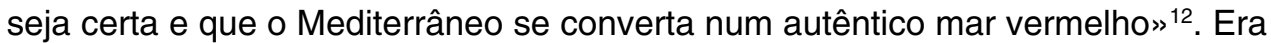
assim que em Março de 1975 um correspondente em Nova lorque do jornal La Vanguardia sintetizava a posição dos EUA face ao eventual contágio revolucionário da revolução portuguesa à vizinha Espanha. Se a revolução portuguesa chegasse a Espanha, mesmo com os esforços feitos pelos partidos comunistas espanhol, italiano e francês no sentido de lutar pela via democrática na Europa Ocidental, teria consequências imprevisíveis na hegemonia do bloco ocidental e na NATO. O Presidente Gerald Ford expressa o sentimento americano perante os acontecimentos no Sul da Europa: «Se um membro da Aliança Atlântica se tornar comunista, (...) isso iria destruir a Aliança Atlântica. Não podemos dar um mau exemplo em Portugal ${ }^{13}{ }^{\text {» }}$.

Num outro registo, pode ler-se no Pueblo que «a Europa Ocidental sentiu medo perante a brilhante e hábil campanha comunista em Lisboa que ameaça converter um país sonolentamente reaccionário noutro politicamente hostil ao Ocidente, com graves repercussões nos membros mais débeis do mesmo, como a Grã-Bretanha e a Itália ${ }^{14}$ ». Victor Marchetti, ex-agente da CIA, numa entrevista ao Pueblo, quando lhe perguntam quais são as actividades da CIA em Portugal, responde que «A única coisa que posso dizer-lhes sobre a situação actual é que a CIA está preocupada com Portugal. A CIA não quer que se repita outro Portugal15»».

O Mediterrâneo «vermelho» era uma ameaça real: em Itália estava em cima da mesa o Compromisso Histórico de Enrico Berlinguer, uma aliança entre o $\mathrm{PCl}$ e a Democracia Cristã; em França, ainda no rescaldo do radicalizado Maio de 68, o Partido Comunista e o Partido Socialista assinam o Programa Comum. Em nenhum destes países os partidos comunistas quiseram tomar o poder por via revolucionária ou dirigir um processo que evoluísse para a expropriação dos meios de produção. Mas as suas votações expressavam uma amplíssima base social, temida pela classe dominante da Europa Ocidental e dos EUA. É neste quadro que se dá a revolução portuguesa, a queda da ditadura dos coronéis na Grécia e que em Espanha se discute se o fim da ditadura se dará por via reformista ou revolucionária.

\section{EL SOCIALISTA}

El Socialista, o jornal do Partido Socialista Obrero Español, recebe euforicamente a revolução de Abril em Portugal. O PSOE foi fundado em 1879 por um gru-

12 La Vanguardia, 23 de Março de 1975

13 In SIMAS, Nuno, Diário de Notícias, 27 de Abril de 2004 (artigo feita com base na desclassificação de documentos internos norte-americanos em 2004).

14 Pueblo, 22/3/1975, Arquivo Histórico-Diplomático, PEA 16/75-311-Informações sobre Portugal na imprensa espanhola.

15 Pueblo, 21/2/1975, Arquivo Histórico-Diplomático, PEA 16/75-311-Informações sobre Portugal na imprensa espanhola. 
po de intelectuais e operários - tipógrafos sobretudo - encabeçados por Pablo Iglésias. Mas o PSOE da transição democrática em Espanha é um partido qualitativamente distinto daquele fundado no século XIX. Entre 13 e 17 de Outubro de 1974 o PSOE reúne-se em Congresso em Suresnes, França. No seguimento da Revolução dos Cravos em Portugal e na certeza de que o fim físico de Franco se aproximava, um grupo de jovens, entre eles Felipe González, Alfonso Guerra e Manuel Chaves, concebe um programa político que pugnava pelo estabelecimento de um regime político de liberdade sindical, política, de reunião e associação e uma economia capitalista. Um modelo claramente europeu e ocidental, apadrinhado por Willy Brandt, François Mitterrand e Bruno Pittermann ${ }^{16}$. Este grupo percebeu que não podia deixar espaço livre à esquerda que seria hegemonizado pelo Partido Comunista Espanhol, que em Julho de 1974 tinha encabeçado a Junta Democrática, a primeira tentativa de um programa de ruptura que unisse a oposição, mas da qual o PSOE não faz parte.

O PSOE é portanto irmão do Partido Socialista português, também ele fundado no coração da social-democracia alemã - ainda Willy Brandt era chanceler - e com um programa idêntico, dirigido por Mário Soares.

A revolução portuguesa é um balão de oxigénio para a oposição anti-franquista e El Socialista espelha isso de forma constante. Nas páginas do El Socialista, entre 25 de Abril de 1974 e 25 de Novembro de 1975, o país mais analisado, depois de Espanha, claro, é Portugal: «el restablimiento de la libertad (...) en Portugal es un gran aliento para el pueblo español», diz o comunicado oficial conjunto do PSOE e da UGT logo a seguir ao 25 de Abril. Alerta também para que a partir daquele momento o franquismo será o pior inimigo de Portugal e fará tudo para obstaculizar o regime português. Num artigo de primeira página intitulado «Portugal y España», o PSOE defende que os dois países têm muito em comum: serem ditaduras de base fascista e autoritária com estruturas jurídicas semelhantes, ligadas por um Pacto Ibérico; militaristas e na Nato ou a esta ligados; repudiadas pelos povos do mundo e pela Comunidade Europeia; com uma imensa mão-deobra a migrar do campo para a cidade. Fica claro, como veremos em mais exemplos que, para o PSOE, sobretudo até ao Verão Quente quando há a máxima crise de Estado do período revolucionário português, Portugal e Espanha são como se de um país se tratasse. De tal forma que El Socialista avisa: quebrou-se um dos pilares do fascismo apoiados pelos EUA ${ }^{17}$. A relação é embrionária. Em Março de 1975, no rescaldo do 11 de Março, o editorial «Portugal, España, Europa» fala da preocupação pela Península «hasta el punto de que la realidad política de los dos países está presente en todos los debates ${ }^{18} »$. Num comunicado conjunto dos so-

16 Willy Brandt: Chanceler alemão entre 1969 e 1974 e líder do Partido Social-Democrata Alemão (SPD); François Mitterrand: secretário-geral do Partido Socialista Francês entre 1971 e 1981; Bruno Pittermann: Presidente da Internacional Socialista entre 1964 e 1976.

17 El Socialista, Segunda Quincena de Mayo de 1974, pp.1 e 3.

18 El Socialista, Segunda Quincena de Marzo, 1974, p. 1 
cialistas portugueses e espanhóis fala-se da construção do socialismo na Península Ibérica e dos povos oprimidos espanhol e grego. Vicente Girbau escreve de Lisboa para El Socialista citando um poema do poeta e resistente espanhol António Machado onde este escreve «La primavera ha venido del brazo de un capitán» e termina o seu artigo dizendo "Quizás pudiéramos también enviar monóculos a

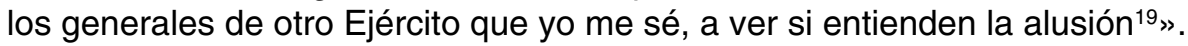

Far-se-ão muitos erros se olharmos para a sociedade espanhola de hoje e a transpusermos para 1974. Encarnación Lemus, no seu estudo sobre a influência externa na transição, «retorna» a 1975: «De un lado, a la altura de 1975, el socialismo como princípio ideológico y como sistema social no estaba desautorizado; la via socialista se estaba intentando en Portugal; por otra parte, todavia existia el Gobierno de la República en el exílio, que reclamaba la legalidad, y los partidos de la oposición, tanto los socialistas como el PCE, eran republicanos ${ }^{20}$ ». Para o PSOE Juan Carlos é uma figura odiosa, a continuação do franquismo, o que é absolutamente contrário à imagem que o rei de Espanha tem hoje: se o franquismo de agora é representado por Árias Navarro, amanhã sê-lo-á por Juan Carlos, defendem os socialistas; «es imposible no identificar monarquía con autoritarismo»; «Además, la persona que se apresta a ostentar la corona ha permanecido a lo largo de estos últimos cinco años a la completa disposición de la Dictadura y de sus desmanes ${ }^{21}{ }^{\prime}$. Não se pode, pelo que aqui vimos, afirmar que o rei é uma figura unificadora e central da transição espanhola visto que o PSOE, um dos principais partidos desta transição, rejeita, de forma pouco contida, quer a monarquia quer Juan Carlos (sabemos que a partir de 1976 a opinião vai paulatinamente mudando até o PSOE e o PCE aceitarem a monarquia).

Um jornal clandestino não está sujeito ao crivo da censura, o que não encurta necessariamente a fronteira entre a verdade, a mentira ou só a omissão. O PSOE tem um programa assumidamente social-democrata mas nas suas páginas mobiliza o marxismo, certamente para dar resposta à radicalização das camadas populares na época e à competição por dirigi-las com o PCE. Há páginas do jornal com fotografias de líderes históricos do marxismo, entre eles Karl Marx e Rosa Luxemburgo. O PSOE vê-se obrigado a mobilizar a teoria marxista e explicá-la aos seus militantes. São um partido de classe, «partido obrero quiere decir pura y simplemente partido de clase. Partido com conciencia de clase, al servicio de la clase social de los trabajadores, privados de los médios de producción, sometidos a la explotación de la burguesia ${ }^{22}$ ». A maior parte dos números de El Socialista tem uma página denominada Terrorismo Oficial em que se escreve sobre a repressão franquista dia a dia em todos os locais de Espanha, mobilizando o conceito mar-

19 El Socialista, Segunda Quincena de Mayo de 1974, pp.1 e 3

20 LEMUS, Encarnación, En Hamelin...La Transición Española más allá de la Frontera, Oviedo, Septem Ediciones, 2001, p. 16.

21 El Socialista, Primera Quincena de Setiembre, 1974, p. 2

22 El Socialista, Segunda Quincena de Julho, 1974, p. 71. 
xista de terrorismo de Estado e deslegitimação da violência oficial. Em Março de 1975 surge uma discussão em torno do conceito de revolução e transição. Comentando uma publicação escrita por Felipe González em 1976, onde havia fotos de Marx, Engels, Lenine, Trotsky, Rosa Luxemburgo, a historiadora Paloma Aguilar encontra a principal explicação na memória que o PSOE e os seus militantes têm da guerra civil: «Era muy difícil relegar a un segundo plano toda esta historia pues constituía uno de los avales más importantes del PSOE para un sector no desdeñable de la sociedad. Para otro, sin embargo, este recuerdo no resultaba especialmente grato. Esta percepción problemática del pasado es lo que hace que el PSOE adopte una actitud ambivalente hacia él ${ }^{23}$ ». Para nós, porém, esta explicação é insuficiente: o comportamento dos partidos políticos é certamente determinado pelo seu passado mas não exclusivamente nem sequer principalmente. A chave para esta explicação encontra-se, para além da sangrenta guerra civil, na radicalização do movimento operário e popular espanhol a partir do final dos anos 60 e na década de 70 e no impulso que esta radicalização teve com a revolução portuguesa que, para além de ser um processo revolucionário num país fronteiriço e num regime irmão, era um processo revolucionário sem sangue pelas condições muito específicas que levaram à queda da ditadura e que implicaram a impossibilidade da classe dominante mobilizar o exército a seu favor. Por isso nas mesmas páginas o PSOE fala de consciência de classe como de construção de uma democracia europeia.

O exército está sempre nas páginas de El Socialista. Nos jornais por nós analisados os socialistas espanhóis olham para 4 exércitos: o de Franco, o dos EUA e da NATO, o do Chile e o de Portugal. E a relação do PSOE com estes exércitos não é a mesma, claro, o que pode explicar a posição ambivalente do PSOE em relação ao exército espanhol, utilizando muitas vezes o exército português como exemplo: umas vezes o PSOE apela ao exército espanhol para que este siga o exemplo do exército português - «el ejército português ha dado una lección de sentido político y cívico ${ }^{24}$ » - outras denuncia o carácter ditatorial e sanguinolento do exército (sem mencionar a que exército se refere) - «Hay que desconfiar de una sociedad democrática que establezca el control democrático por un aparato de fuerza ${ }^{25}$ ». A ditadura em Portugal caiu pelas mãos do exército, o mesmo exército que por exaustão de 13 anos de guerra não conseguir recompor-se e reprimir o processo revolucionário e tudo isto representa de facto uma novidade, espelhada pelos dirigentes do PSOE. O exército conhecido era o de Franco, do levantamento de 18 de Julho e, sempre presente nas páginas dos jornais, o exército chileno que tinha derrubado de forma brutal o governo de Salvador Allende. Era de facto uma novidade na história do século XX um exército que, na sua larga maio-

${ }^{23}$ Aguilar, Paloma Fernández, Memoria y Olvido de la Guerra Civil Española, Madrid, Alianza Editorial, 1996, p. 323.

24 El Socialista, Primera Quincena de Junio 1974, pp. 2.

25 El Socialista, Segunda Quincena de Júlio, 1975, p.6. 
ria, se recusava a actuar em nome da contra - revolução - esta análise só é correcta até ao 25 de Novembro de 1975.

Até aos meses de Maio e Junho de 1975 a atitude do PSOE é a de valorizar os aspectos semelhantes entre a ditadura portuguesa e a espanhola e, embora não omitindo as diferenças (existência de uma guerra civil em Espanha, inexistência de uma guerra colonial em Espanha), o PSOE procura sempre olhar para a Península como um todo envolvido num processo de democratização que tem início em Portugal e fim em Espanha. De tal forma que a imprensa portuguesa é vista como fonte de legitimação para os actos do PSOE. Um artigo debruça-se exclusivamente sobre a forma como a imprensa portuguesa recebeu a notícia da fundação da Plataforma de Convergência Democrática ${ }^{26}$. Numa exposição feita pelo relator sobre a situação internacional em Outubro de 1974, este pede ajuda aos partidos socialistas da II Internacional para fazer cair a ditadura espanhola, saúda a independência de Guiné-Bissau, Moçambique e Angola, rejeita a Junta Militar chilena, saúda Portugal e a Grécia e defende a resolução da crise palestiniana ${ }^{27}$.

A partir de Janeiro de 1975 surgem as primeiras críticas, embora ténues, a Cunhal: no congresso do Partido Socialista português destacou-se o «uso (o abuso) de los comunistas españoles, como instrumento de choque contra los comunistas portugueses - consentida por otra parte, por los delegados comunistas españoles - en base a las actitudes de Cunhal que parece decidido a retrasar el proceso electoral ${ }^{28}$ ". Esta frase e outras semelhantes que se escrevem nas páginas do jornal do PSOE reproduzem também o conteúdo das relações entre os partidos comunistas e socialistas na Península Ibérica. O PSOE que, junto com o PCE, procura uma política unitária anti-franquista que conduza à democratização - que vai ser consolidada no primeiro trimestre de 1976 com a Convergência Democrática - não tem a rivalidade com o Partido Comunista que tem o Partido Socialista português. Por outro lado, os comunistas portugueses e espanhóis tiveram, durante a revolução portuguesa, relações conflituosas. Num artigo intitulado «Socialistas y comunistas en el sur de Europa ${ }^{29}$ ", o PSOE defende que os comunistas são uma necessidade na vida política da Europa do Sul e que devem ter como prioritário o acordo com as forças progressistas de esquerda e não com a burguesia. Para o PSOE os comunistas que tinham feito alianças com a burguesia são os do PCI no Compromisso Histórico e os do PCE com a Junta Democrática facto que também nos pode dar pistas sobre a relutância do PSOE em criticar mais cedo Álvaro Cunhal e o PCP. Não nos esqueçamos, como já referido, que os Partidos Comunistas da Península tinham uma relação conflituosa: se estas relações conflituosas se prendem com diferenças estratégicas - adesão ao eurocomunismo, fidelidade à alegada política revolucionária dos soviéticos-, como defendem poli-

26 El Socialista, Primera Quincena de Agosto de 1975, p.4.

27 El Socialista, Segunda Quincena de Octubre 1974, p.6.

28 El Socialista, Segunda Quincena de Enero, 1974, p.11.

29 El Socialista, Primera Quincena Abril, 1975, p. 5. 
tólogos como Carlos Cunha ${ }^{30}$, entre outros, ou se estas diferenças são tácticas e o afastamento de ambos os partidos prende-se com o curso revolucionário de Portugal, é um assunto que ainda não foi suficientemente estudado pela investigação académica, pelo que é difícil tirar conclusões, para já. $O$ que sabemos é que o PSOE tenta manter boas relações com o PCP até ao início do Verão Quente (Maio) - e que por sua vez Mário Soares recebe Santiago Carrillo em Lisboa.

Trata-se de relações que temos mais dificuldade em compreender porque não encaixam de forma exacta nas famílias políticas o que, a nosso ver, pode ser explicado pela instabilidade, mudança, ritmo de acontecimentos sociais rapidíssimo que um processo revolucionário introduz. A verdade é que em Portugal, a 25 de Novembro de 1975, o PCP aceita a normalização democrática e fará parte, com o PS, dos partidos que constroem uma democracia representativa no quadro de uma economia de mercado e que, 3 semanas depois, se iniciam em Espanha os contactos para a unificação da Junta Democrática (dirigida pelo PCE) e da Plataforma de Convergência Democrática (dirigida pelo PSOE) na Coordinación Democrática.

A partir de 11 de Março de 1975 o PSOE inverte o discurso da Península una e tenta distanciar a realidade portuguesa da espanhola. Agora as diferenças são valorizadas: «Desde Europa la evolución política española seguirá el modelo portugués. Este pensamiento se fundamenta en la creencia de que los dos pueblos tan próximos, sometidos a dos regímenes dictatoriales, han de tener un desarrollo histórico similar. Sin embargo, la realidad económica, social y política de los dos países es muy diferente ${ }^{31}$ ». Recorde-se que, como lembra Sanchez Cervelló, é a partir desta data que o PSOE passa a ser tolerado pelo regime e autorizado por exemplo, a fazer acções de rua com os seus símbolos ${ }^{32}$. É também aqui, com a radicalização do processo português, que o governo franquista compreende que deve mobilizar o PSOE contra o PCE e evitar a radicalização da situação espanhola.

Já na questão do debate sobre a unicidade sindical em Portugal o PSOE tinhase mostrado menos entusiasta com a evolução do processo revolucionário português. Sobre a polémica que levou à aprovação pelo governo da lei da unicidade sindical a 21 de Janeiro de 1975, o PSOE alerta que «la única fórmula aceptable es la de permitir que los trabajadores decidan com absoluta libertad la forma en que han de organizarse sindicalmente ${ }^{33}$ ». O PSOE lamenta também as divergências entre Serra e Soares, comentando a cisão da Frente Socialista Popular. Para além das opiniões do PSOE devemos reforçar com estes exemplos uma con-

30 CUNHA, Carlos A., The Portuguese Communist Party's Strategy for Power, 1921-1986, Nova Iorque, Garland Publishing, Inc., 1992.

31 El Socialista, Segunda Quincena de Marzo, 1975, p. 4

32 CERVELLÓ, Joseph Sanchéz, A Revolução Portuguesa e a sua Influência na Transição Espanhola (1961-1976), Lisboa, Assírio e Alvim, 1993, p. 376

${ }_{33}$ El Socialista, Primera Quincena de Febrero, 1975, p.9. 
clusão já avançada: a vida interna do PS é parte da política do PSOE. Relatando uma reunião do PS em Lisboa, o PSOE diz que enviou 300 delegados $^{34}$ a essa reunião, realizada na última semana de Março; mesmo descontando um possível exagero dos números, estamos perante uma relação muito estreita entre os dois partidos e um forte interesse dos espanhóis pelo processo revolucionário português. A vida interna do PS era essencial para o PSOE. E o PS será cada vez de forma mais explícita o partido irmão do PSOE, que reforça laços de confiança com os socialistas portugueses através de críticas, agora explícitas, ao Partido Comunista Português, denunciando-o como a via «autoritarista para o socialismo». Comentando a crise de Agosto em torno do V Governo, o PSOE denuncia um «conluio» entre Vasco Gonçalves e Varela Gomes para controlar o país e conclui que «El Partido Socialista Portugués es la única organización política que puede garantizar un 'socialismo en libertad ${ }^{35}$ '». No número seguinte do El Socialista defende-se o Documento dos 9, acusa-se o Partido Comunista de querer ocupar pontoschaves da administração local e central, dos meios de comunicação e das Forças Armadas e apela-se à construção de uma sociedade socialista pluralista e democrática que sirva de «ejemplo inmediato para el resto de los países latinos ${ }^{36}$ ».

A manifestação que levou ao assalto ao consulado de Espanha no Porto e à Embaixada de Espanha em Lisboa, vista como «o incidente mais grave entre a Espanha e Portuga| ${ }^{37}$ ", segundo Sanchéz Cervelló, é vista pelo PSOE apenas em 4 linhas junto a toda uma série de manifestações mundiais, em mais de 20 cidades do Mundo, contra a condenação à morte de 5 militantes anti-franquistas. Não é um assunto de conflito, de crise diplomática, mas apenas mais uma expressão popular do movimento internacional contra Franco.

Chega-se a Novembro e o PSOE está do lado do PS e do Grupo dos 9 e da «autoridad y disciplina al servicio del poder constitucional legitimamente constituído». A partir deste mês, e apesar de continuar a escrever-se muito sobre Portugal, é manifestamente menor a preocupação com a evolução da situação política portuguesa. Agora, mais do que nunca, o centro das atenções é Espanha, agora que «el último dictador fascista de Europa ha muerto ${ }^{38}$ ». O PSOE nota a coincidência do dia da morte de Franco com o início dos julgamentos de Nuremberga 30 anos antes, a 20 de Novembro de 1945.

34 El Socialista, Primera Quincena de Abril, 1974, s/página.

35 El Socialista, Segunda Quincena de Agosto, 1975, p.2.

36 El Socialista, Primera Quincena Setiembre, 1975, pp. 6 e 7.

37 CERVELLÓ, Joseph Sanchéz, A Revolução Portuguesa e a sua Influência na Transição Espanhola (1961-1976), Lisboa, Assírio e Alvim, 1993, p. 353.

38 El Socialista, Segunda Quincena de Noviembre, 1975, p. 2 


\section{COMBATE}

Combate era o jornal da LCR, Liga Comunista Revolucionária, um partido político espanhol trotskista fundado em 1971. Era a secção espanhola do Secretariado Unificado da IV Internacional. De dimensão relativamente pequena quando comparado com o PCE ou o PSOE, mas bastante superior em número de militantes e influência ao POUM - influência conquistada sobretudo depois do Maio de 68 em França que originou o aumento dos partidos trotskistas e do seu número de militantes na Europa Ocidental, a LCR, pela sua trajectória internacionalista tem uma especial atenção pelos acontecimentos políticos internacionais, entre eles a revolução portuguesa.

Não foi possível no arquivo da Fundação Pablo Iglésias resgatar todos os números do Combate referentes a este período. O primeiro número que temos é de Junho de 1974. Nele, o Combate dedica as suas páginas à «Hora da Verdade» em Portugal. Analisam-se aqui vários momentos e actores da revolução portuguesa com especial destaque para o PCP, desde 25 de Abril do mesmo ano. Históricos inimigos dos partidos comunistas ligados à URSS e ao estalinismo, os trotskistas da LCR começam por acusar o PCP de ser um partido reformista, estalinista, que se centra na denúncia da greve como uma «arma dos trusts» - 0 Combate vê na argumentação de Cunhal a sombra de Maurice Thorez, dirigente histórico do Partido Comunista Francês - e das mobilizações de massas como a "extrema esquerda a fazer o jogo da reacção ${ }^{39}$. O artigo prossegue denunciando o facto de o PCP ter abandonado a luta pelos 6000 escudos de salário mínimo. Para a LCR trata-se por sua vez de claudicar aos sectores pequeno-burgueses do país, nomeadamente às pequenas e médias empresas que, segundo o PCP, entrariam na ruína se tivessem que pagar os 6000 escudos de salário mínimo. Para - Combate não há diferenças substanciais entre o PCP de Cunhal e o PCE de Santiago Carrilho - ambos partilham a mesma estratégia democrática, variando na táctica que é mais ou menos mobilizadora das massas conforme a situação da luta de classes.

Algumas destas acusações do trotskismo espanhol - e relembra-se aqui que se trata de uma organização espanhola e de um jornal espanhol - encontram factos pela frente. Logo a 26 de Abril de 1974, o PCP publica um Comunicado Sobre o Movimento Militar de 25 de Abril onde saúda calorosamente o MFA e alerta que «Existe o perigo de um contra-golpe dos elementos mais reaccionários ${ }^{40}$ ». A 4 de Maio, já depois da imensa mobilização do $1 .^{\circ}$ de Maio que juntou na rua mais de meio milhão de pessoas com reivindicações que já não se limitavam ao plano das liberdades democráticas, mas incluíam por exemplo a exigência de um salário mínimo de 6000 escudos, o Comité Central do PCP aprova uma resolução política

39 Combate, Junho de 1974, pp 15-17.

40 Comunicados do Comité Central do PCP, Documentos Políticos do Partido Comunista Português, Lisboa, Edições Avante, 1975, p.17. 
onde afirma que, para além do oportunismo de direita é igualmente perigoso «o esquerdismo, que se expressa sobretudo na impaciência que não tem em conta a correlação de forças e em atitudes e acções divisionistas e desagregadoras ${ }^{41}$ ».

Para a LCR a actuação do PCP é central. O Avante é lido pelos trotskistas espanhóis. No seu artigo de denúncia do PCP fazem-se amplas citações do Avante para concluir que o PCP, ao denunciar o radicalismo da extrema esquerda e não apoiar, por exemplo, a greve dos 25000 trabalhadores dos CTT, está a pôr em causa um projecto revolucionário em Portugal e a unidade da classe operária, indispensável para a revolução socialista, de que os trotskistas são partidários.

O artigo, que não menciona o PS a não ser uma vez para o classificar de «reformista", dedica-se depois a analisar a negociação com o PAIGC sobre a independência da Guiné-Bissau. Estamos em Junho e ainda não estava claro que tipo de descolonização iria para a frente. A LCR clama pela independência «imediata, incondicional e total» das colónias portuguesas. Mais de metade do artigo é um apelo da FSMR, Frente de Soldados e Marinheiros Revolucionários, aos camaradas soldados e marinheiros - o partido destaca o carácter progressivo das organizações democráticas no seio do exército - onde se apela à constituição de comités revolucionários de soldados e marinheiros e à sua participação em manifestações que possam, juntamente com os trabalhadores, tomar o poder. Trata-se de resgatar as organizações de duplo poder, caras ao marxismo, que põem em causa o poder do Estado, hegemonizado pela classe burguesa, e o minam através de organizações autónomas de trabalhadores.

A revolução em Portugal contribui, sem dúvida, para a radicalização do processo espanhol: o horizonte destes militantes era o de quem estava perante a possibilidade de abertura de uma crise revolucionária em Espanha e não de uma transição que acabou por ocorrer em moldes muito mais pacíficos e elitistas: em Setembro de 1975, a LCR apela à «organização da violência revolucionária a partir dos organismo unitários ${ }^{42}$ », nas fábricas, bairros e estabelecimentos de ensino. Enquanto se saúdam as greves em Portugal, a LCR, em quase todos os Combate apela à greve geral de massas para derrubar o franquismo.

«Agora» era o título em 10 de Setembro de 1975, amplamente dedicado a tentar impedir aquelas que viriam a ser as últimas mortes do franquismo, cinco militantes da ETA e da FRAP, e que levaram em Portugal ao assalto à Embaixada de Espanha, no Porto e em Lisboa, a 27 de Setembro de 1975.

Embora, como já referimos, não tenhamos tido acesso a todos os números do Combate no período cronológico que estudámos, não deixa de ser curioso verificar que, mesmo nos poucos números a que tivemos acesso, os acontecimentos portugueses para estes militantes não são mais importantes que as repercussões po-

41 Idem, p.24.

42 Combate, 10 de Setembro de 1975. 
líticas do Maio de 68 nas universidades europeias, o golpe de Pinochet no Chile, o "compromisso histórico» italiano, ou a onda de greves que naquele momento se vivia na Grã Bretanha. Ao contrário do jornal do PSOE, para quem a revolução portuguesa tem nas suas páginas muito mais importância que qualquer um destes acontecimentos, para os trotskistas espanhóis não é assim. Isso mostra-nos, pelo menos como conclusão provisória, que a bandeira da revolução portuguesa está longe de ser uma preocupação central exclusiva dos partidos de extrema-esquerda ou das organizações minoritárias. Pelo contrário, é às grandes organizações políticas de esquerda espanhola que a revolução aparece mais como uma lição para uma Espanha que tem de se democratizar para impedir um processo revolucionário semelhante ao português.

\section{LA BATALLA}

La Batalla era o órgão oficial do POUM, Partido Obrero de Unificación Marxista. O POUM era um partido operário marxista de carácter revolucionário crítico da linha estalinista. Entre 1937 e 1938, o POUM é ilegalizado por exigência do PCE e o seu principal dirigente, Andreu Nin, assassinado, num processo que teve a participação dos serviços secretos soviéticos. Com o fim da guerra civil seguiuse um período de perseguição, prisão e assassinato dos principais quadros do POUM, repressão que se prolongou no Sul de França durante o governo de Vichy. A direcção do POUM acaba por se exilar em Paris, mas o partido sofre várias cisões, inclusive de dirigentes que acabam por aderir ao PSOE (Julian Gorkín, Ignacio Iglesias), também na clandestinidade, como vimos. O POUM que chega à transição é um pequeno partido, fragilizado, que acaba por se auto-extinguir em 1980.

Apenas dois números estão disponíveis de $L a$ Batalla ${ }^{43}$ o primeiro dos quais surge em Dezembro de 1975, já depois do fim da própria revolução. Este aspecto é revelador da pouca importância que o POUM tinha já nesta época como partido político. No entanto, os dois números dedicam uma ampla análise à revolução portuguesa, considerada uma revolução democrática burguesa que abriu no país a possibilidade de uma revolução de carácter socialista. É curioso desde logo a percepção que na altura este partido tinha da própria revolução - o 25 de Novembro não é visto como o fim da revolução, mas apenas como «un freno [travão] momentáneo en el processo revolucionário português ${ }^{44}$ ». Neles o POUM apresenta o seu projecto socialista para a Espanha que passa, no imediato, pela conquista de todas as liberdades democráticas.

43 É possível que haja um número anterior a este de 74 mas, se sim, não consta dos arquivos.

44 La Batalla, Ano XXX, No. 182, p. 1. 


\section{MUNDO OBRERO: «PORTUGAL É ESPANHA»}

O Partido Comunista de Espanha recebe com entusiasmo a revolução portuguesa. A participação dos comunistas portugueses no governo com a burguesia nacional alentava o PCE que, apesar da tragédia da guerra civil espanhola e da derrota da revolução, nunca questionou a estratégia de frente popular.

As páginas do Mundo Obrero, jornal do PCE, enchem-se de notícias sobre Portugal. De todos os acontecimentos internacionais há três que marcam as páginas do jornal: a revolução portuguesa, em primeiro lugar; a ditadura de Pinochet no Chile; e a derrota norte-americana no Vietname. Santiago Carrillo e outros dirigentes do PCE escrevem que Portugal é exactamente o exemplo a seguir por todos em Espanha. No dia 4 de Junho de 1974, a capa de Mundo Obrero é feita de uma entrevista a Santiago Carrillo que tem como base a situação portuguesa. A citação é elucidativa: «Ainda que algumas pessoas tenham dito que deve evitar-se que Espanha se portugalize, parece-me que a portugalização de Espanha é inevitável ${ }^{45}$ ». Dolores Ibarruri, a Pasionaria, escreve em Julho de 1974: «Portugal é hoje uma mola que pode fazer saltar as barreiras do medo e da desconfiança e da incompreensão que tem vindo a travar a democratização de Espanha ${ }^{46}$ ».

A mola saltou quase de imediato. No dia 29 de Julho de 1974, o Partido Comunista de Espanha forma a Junta Democrática de Espanha, que largamente dirige, e integrava ainda o PTE (Partido do Trabalho de Espanha), o Partido Carlista, as Comisiones Obreras e o PSP (Partido Socialista Popular).

O programa da Junta incluía a formação de um governo provisório, defesa das liberdades democráticas (políticas, sindicais, de reunião e associação); realização de uma consulta popular sobre a forma de Estado; reconhecimento - submetido à unidade do Estado espanhol - das comunidades autónomas; respeito pelos acordos internacionais e pelos princípios da coexistência pacífica.

Mas Portugal só será um exemplo para Espanha enquanto a revolução não se radicaliza. Depois de 11 de Março de 1975, em que no horizonte da revolução portuguesa estão de facto tarefas socialistas e não já maioritariamente democráticas - em que se dão, por exemplo, as nacionalizações da banca e dos seguros, as ocupações de grandes propriedades se generalizam, uma parte dos capitalistas foge do País -, o PCE distancia-se de Portugal. Distancia-se também do PCP e consolida os laços com Enrico Berlinguer e o eurocomunismo.

Carrillo passa a ignorar a revolução portuguesa - exactamente no período em que ela se radicaliza - e quando se refere a Portugal é para salientar as diferenças face a Espanha: a Espanha não é Portugal, desde logo porque não passou por uma guerra colonial, mas também porque Portugal é um país atrasado, terceiro-

45 Mundo Obrero, 4 de Junio de 1974, p.1.

46 Mundo Obrero, 3 de Julio de 1974, p.5. 
mundista, sem uma "direita civilizada», tecnocrática, capaz de se unir às forças progressistas e realizar uma transição democrática pacífica; os espanhóis fizeram a guerra civil e estão imunizados contra os extremismos.

O Verão de 1975 em Portugal, que ficou para a história como o «Verão Quente", marca o momento de maior tensão entre as classes que se debatiam na revolução portuguesa: o MFA cinde-se; o PS joga tudo por tudo para travar a revolução formando um bloco social com a ala moderada do MFA, os sectores mais reaccionários e a Igreja que, sob a capa da luta contra a pretensa sovietização levada a cabo pelo PCP, se mobilizam contra os trabalhadores e os jovens que faziam a revolução, ou seja, aqueles que diariamente ocupavam terras, autogeriam fábricas e empresas, ocupavam faculdades e casas. Este bloco ganha confiança para acabar com a aliança até aí formada com o PCP e os militares mais à esquerda do MFA e deixa cair o IV Governo Provisório, deixando os comunistas sozinhos no Governo, contra a vontade do próprio PCP, que faz todos os esforços para contrariar a situação que levará à formação do V Governo Provisório (Cunhal, 1976: 15-17).

Em Julho de 1975, em plena crise revolucionária em Portugal, a capa do Mundo Obrero é feita já não do exemplo português, mas dos discursos de Carrillo e Berlinguer, discursando para uma multidão em Livorno, na Itália. Os líderes apelam à construção de uma Europa democrática, ao «socialismo do nosso tempo». O título de capa é elucidativo: «Socialismo na Democracia. Os Clichés Sectários Isolam a Vanguarda». Pode ler-se no jornal que: «A defesa da democracia, o caminho para o socialismo, a paz, a cooperação mundial, passam pela aliança dos comunistas com os socialistas, social-democratas, católicos e outras forças do progresso. E esta é, na nossa opinião, a única política de classe possível hoje na Europa. A repetição dos velhos clichés sectários, à margem do tempo, não serve para mais nada a não ser isolar a vanguarda, dividir as forças do progresso e preparar novas derrotas para o movimento operário " ${ }^{47}$.

Na boleia da crise revolucionária portuguesa, o PCE assume o compromisso com o eurocomunismo, distancia-se definitivamente de Moscovo e aproxima-se da social-democracia europeia, dos franceses que ensaiavam o Programa Comum, dos italianos do Compromisso Histórico. Franco estava moribundo com Parkinson: morreria no dia 20 de Novembro de 1975. Carrillo afasta-se de Cunhal, não só porque já se tinha afastado da URSS, mas porque Cunhal aparece como o bode expiatório de toda a política que acabaria nos Pactos de Moncloa. Carrillo acena a Espanha com o fantasma da sovietização, como forma de conter os conflitos laborais.

47 Mundo Obrero, n 24, 4ª semana de Julio de 1975. 


\section{CONCLUSÃO}

Em Abril de 1974 uma revolução irrompe em Portugal. Três meses depois, no dia 29 de Julho, o PCE funda a Junta Democrática de Espanha. No dia 11 de Março de 1975, um golpe de direita é derrotado em Portugal, abrindo caminho à radicalização da revolução. No dia 12 de Março, um dia depois, o PSOE é legitimado em Espanha. No Verão de 1975, Portugal está no meio de uma crise revolucionária. O PSOE funda nesse Verão, em Junho, a Plataforma de Convergência Democrática, com um programa semelhante ao da Junta. O PCE faz um comício público com Berlinguer a favor da democracia. No dia 20 de Novembro Francisco Franco morre. No dia 25 de Novembro de 1975, um golpe dirigido pelo PS dá início à contra-revolução (democrática) em Portugal. Três semanas depois, em Espanha, PCE e PSOE encontram-se para unificar a Junta e a Plataforma na Coordenação Democrática, que é negociada em Dezembro de 1975 e formalizada em Março de 1976.

No dia 18 de Novembro as Cortes Gerais em Espanha fazem aquilo que ficou conhecido como «haraquiri [suicídio] das cortes franquistas». Aprovam uma lei que implica a sua dissolução, abrindo portas para a institucionalização daquilo que já era um facto: a ditadura franquista não tinha sobrevivido à revolução portuguesa.

Os Pactos de Moncloa, assinados pelo PCE e pelo PSOE, junto com os partidos de direita, são o acordo central que termina este processo, no fim de 1977. A sua espinha dorsal é o modelo económico, a economia de mercado. O texto do pacto está dividido em dois grandes pontos: acordo sobre o programa de saneamento e reforma da economia e acordo sobre o programa de actuação jurídica e política.

Trazer os partidos políticos clandestinos e oposicionistas para a arena da história é essencial para a compreensão da história peninsular dos anos 70 . A revolução portuguesa é um impulso aos movimentos sociais em Espanha e abre a necessidade de iniciar uma transição pactada, que será levada a cabo por um sector do franquismo, o PCE e o PSOE. A transição espanhola abafou a perspectiva de uma crise revolucionária em Espanha, o que só foi possível com o acordo dos principais partidos oposicionistas, PSOE e PCE.

A análise da imprensa da época e a comparação desta com alguma bibliografia publicada já sobre o tema permitem-nos algumas conclusões: desde logo pudemos reafirmar a centralidade que o desenvolvimento da crise revolucionária em Portugal tem para a Espanha, sobretudo para o PCE e o PSOE, mais ainda, segundo os nossos dados, do que para sectores da própria extrema-esquerda. Portugal aparece aliás, até Março de 1975, não como um país vizinho, mas como parte de um corpo único que seria a Península Ibérica. César Oliveira, no seu estudo sobre Portugal e Espanha no século XX escreve que é impossível coexistirem na Península Ibérica por períodos prolongados «regimes políticos caracterizados por normativos e princípios claramente contraditórios ${ }^{48} »$. A guerra civil espanhola e

48 OLIVEIRA, César, Cem Anos nas Relações Luso-Espanholas. Política e Economia, Lisboa, Edições Cosmos, 1995, pp. 15 
a transição são os dois exemplos mais notórios deste modelo que, pelos menos desde as revoluções liberais, não encontra excepção. Mas, como vimos nestes jornais, a influência aqui não se mede por uns poucos anos, como nas revoluções liberais ou no republicanismo, mas em dias. Para o PSOE a Península é um corpo indivisível e assim se manterá até Março de 1975, altura em que a revolução portuguesa se radicaliza e o próprio PSOE é legitimado pelos franquistas. Só neste momento o PSOE passa a criticar o PCP, mas ainda de forma contida. O PCE tem uma política semelhante e deixa de ter a revolução portuguesa como exemplo quando esta passa a ser uma revolução nitidamente de carácter social, em que o modo de produção e não só o regime político são contestados.

Outras conclusões foram avançadas ao longo do texto. Ao contrário do senso comum actual, o rei de Espanha Juan Carlos, ainda hoje chefe do Estado Espanhol, é visto como um homem de Franco pela oposição e assim se manterá até 1976. O assalto à Embaixada de Espanha em Setembro de 1975, levado a cabo por parte da extrema-esquerda portuguesa, é um acto de solidariedade anti-franquista que pouco ou nenhuma atenção especial merece por parte de Espanha, apesar de, como já referimos, ser visto a posteriori pelos historiadores como um momento de crise entre os dois Estados. Há um desfasamento entre a mobilização de rua e as instituições que este episódio revela, desfasamento que nos deve chamar a atenção para a necessidade de multiplicar as fontes para a compreensão da realidade, numa altura em que abundam os trabalhos historiográficos que privilegiam as fontes institucionais.

O tempo das instituições, durante uma revolução, não é o tempo das mobilizações sociais. Num trabalho que realizámos sobre toda a imprensa enviada pela Embaixada de Madrid e o Consulado de Barcelona para Lisboa ${ }^{49}$, não havia um único exemplar da imprensa clandestina e no entanto a transição faz-se com e por causa da participação do PCE e do PSOE. Se o historiador tivesse confiado exclusivamente nas fontes do Ministério dos Negócios Estrangeiros português teria ficado sem qualquer fonte oficial do PCE ou do PSOE. Outro exemplo deste trabalho revela-nos que o ritmo dos sujeitos sociais, nomeadamente das largas camadas da população, não é o mesmo dos sujeitos representativos (instituições estatais, partidos políticos, sindicatos). Embora a Constituição espanhola só tenha entrado em vigor em 1978, a partir de Junho de 1974 os jornais, apesar de ilegalizados, já não reflectem uma ditadura com um amplo e sanguinário aparelho repressivo: fazem-se apelos a greves gerais; mobilizam-se as universidades; exigem-se amnistias; recusase a monarquia. Embora institucionalmente o regime franquista em 1974 não tenha sofrido qualquer alteração, a oposição tem a iniciativa política, está na ofensiva.

A influência que a revolução portuguesa teve na transição espanhola deve também ser vista à luz das diferenças que existiam entre os dois países. E elas são duas: o desfecho da guerra civil espanhola implicou a morte ou o exílio de milhares

49 VARELA, Raquel, (2005) «De Lisboa a Moncloa. A Revolução de Abril e a Transição Espanhola», in História, n 82 , Dezembro 2005. 
de quadros dirigentes da República, toda uma geração, e esse factor teve obviamente impacto em 1974-1975 quando se tratou de reorganizar a oposição para dirigir a explosão social vivida em Espanha nesse período; o outro factor, mais relevante, é que Portugal teve uma guerra prolongada, o exército derrubou a ditadura e foi incapaz de reprimir a revolução. Importantes sectores do exército português, provavelmente por impulso das lutas de libertação nacional (uma revolução anticolonial que é, por via do exército, exportada para a metrópole), aderem inclusive aos sectores revolucionários. Em Espanha, a auto-organização do exército com um programa democrático foi residual, corporizada na UMD, Unión Militar Democrática, e também ela influenciada pelo programa do MFA. Mas o grosso do exército estava com os franquistas.

\section{BIBLIOGRAFIA}

AGUILAR, Paloma Fernández, Memoria y Olvido de la Guerra Civil Española, Madrid, Alianza Editorial, 1996.

ARCARY, Valério, As Esquinas Perigosas da História. Situações Revolucionárias em Perspectiva Marxista, São Paulo, Xamã, 2004

BALFOUR, Sebastian, História Concisa de Espanha (Coord. Raymond Carr), Lisboa, Europa-América, 2004, pp. 247.

BARRETO, António, Portugal Contemporâneo (Coord. António Costa Pinto), Lisboa, Dom Quixote, 2005, pp. 146.

BERLINGUER, Enrico, Do Compromisso Histórico ao Eurocomunismo, Edições Antídoto, Lisboa, 1977.

CARRILO, Santiago, Eurocomunismo y Estado, Editorial CRÍTICA, Barcelona, 1977.

CERVELLÓ, Josep Sánchez, A Revolução Portuguesa e a sua Influência na Transição Espanhola (1961-1976), Lisboa, Assírio e Alvim, 1993.

CUNHA, Carlos A., The Portuguese Communist Party's Strategy for Power 1921-1986, Garland Publishing, Inc. New York \& London, 1992.

HARMAN, Chris, A Peoples's History of the World, London and Sydney, Bookmarks,2002

LEMUS, Encarnación, En Hamelin...La Transición Española más allá de la Frontera, Oviedo, Septem Ediciones, 2001.

LLUCH, Ernest, «Transición Económica Y Transición Política: La Anomalia 1978-1980» in História de la Transición 1975-1986 (Eds Javier Tusell y Álvaro Soto), Madrid, Alianza Universidad, 1996, pp.252.

MAMMARELLA, Giuseppe, Historia de Europa Contemporánea desde 1945 hasta Hoy, Barcelona, Ariel, 1996.

MARTINS, Hermínio, Classe, Status e Poder, Lisboa, ICS, 1998, pp.113.

MUÑOZ, Rafael Durán, Contención y Transgresión, Las Movilizaciones Sociales y el Estado en las Transiciones Española e Portuguesa, Madrid, CEPC, 2000.

OLIVEIRA, César, Cem Anos nas Relações Luso-Espanholas. Política e Economia, Lisboa, Edições Cosmos, 1995, pp. 15

POULANTZAS, Nicos, A Crise das Ditaduras. Portugal, Grécia, Espanha, Lisboa, Presença, 1975.

SAMPERE, Xavier Domènech, «El Cambio Político (1962-1976). Materiales para una Perspectiva desde abajo» in Historia del Presente, $\mathrm{n}^{\circ}$ 1, 2002, pp.46-67.

VARELA, Raquel, (2005) «De Lisboa a Moncloa. A Revolução de Abril e a Transição Espanhola», in História, no 82, Dezembro 2005.

VITULLO, Gabriel E. «Transitologia, consolidologia e democracia na América Latina: uma revisão crítica». Rev. Sociol. Polit. [online]. 2001, no. 17 [citado 2007-02-12], pp. 53-60. Disponível em: <http://www.scielo.br/scielo.php?script=sci_arttext\&pid=S0104-44782001000200006\&lng= pt\&nrm=iso>. ISSN 0104-4478. doi: 10.1590/S0104-44782001000200006

WALLERSTEIN, Immanuel, The Essential Wallerstein, New York, The New Press, 2000.

WALLERSTEIN, Immanuel, «La Construcción Política del Islam en el Sistema-Mundo Moderno» in Puntos de Vista. Cuadernos del Observatório de las Migraciones y de la Convivência Intercultural de la Ciudad de Madrid, n 7, Año II, Octubre 2006, p.11. 